\title{
Glow-discharge-created electron beams: Cathode materials, electron gun designs, and technological applications
}

\author{
J. J. Rocca, J. D. Meyer, M. R. Farrell, and G. J. Collins \\ Department of Electrical Engineering, Colorado State University, Fort Collins, Colorado 80523
}

(Received 21 July 1983; accepted for publication 4 October 1983)

The operating characteristics of glow-discharge-created electron beams are discussed. Ten different cathode materials are compared with regard to maximum electron beam current achieved and the beam generation efficiency as measured calorimetrically. Specific electron gun designs are presented for a variety of applications that include: cw ion laser excitation; electron beam assisted chemical vapor deposition of microelectronic films; and wide area annealing of ionimplantation damage to silicon substrates. The use of sintered metal-ceramic (e.g., $\mathrm{Mo}-\mathrm{Al}_{2} \mathrm{O}_{3}$ ) cathodes to generate multikilowatt electron beams in a pure noble gas discharge is reported. Cathode materials with high secondary electron emission coefficients by ion bombardment allow for electron beam production in glow discharges at $50 \%-80 \%$ generation efficiency values.

\section{INTRODUCTION}

The most common way of producing high voltage direct current electron beams involves thermionic electron emission and subsequent acceleration at background pressures below $10^{-4}$ Torr. Consequently, the use of complex differential pumping systems is usually required in any attempt to inject this vacuum generated electron beam into an experimental chamber containing gases at pressures in excess of 1 Torr.

This paper summarizes our work in direct plasma generation of kilovolt electron beams in a $10^{-1}$ to 3.0-Torr ambient using a glow discharge and secondary electron emission from a cold cathode. In the past, glow discharge electron beams have been used in material processing, welding, melting, and heat treatment. This previous work was discussed by Dugdale ${ }^{1}$ and Boring ${ }^{2}$ as well as by Hurley. ${ }^{3}$ More recently, new technologies such as the excitation ${ }^{4-8}$ of $\mathrm{cw}$ ion lasers, the deposition of thin microelectronic films, ${ }^{9}$ and electron beam annealing of ion-implantation damage ${ }^{10}$ have also required direct current electron beams operating in ambient pressures of 1 Torr. In this paper we present glow discharge electron guns designed especially for these three new purposes as well as electron beam discharge $I-V$ characteristics as a function of pressure and electron beam generation efficiency. Different cathode materials are compared and the use of sintered refractory metal-ceramic oxide cathode materials is reported. Finally, we briefly discuss new applications of glow discharge electron beams.

\section{GLOW DISCHARGE ELECTRON GUNS AND THEIR OPERATION}

Glow discharge electron guns can be divided into two groups: "hollow cathode" or internal plasma electron generation types and "front face emission" or secondary electron emission types. Figure 1(a) shows a hollow cathode glow discharge electron gun which we have designed for the excitation of $\mathrm{cw}$ lasers. ${ }^{11}$ In this type of electron gun, the plasma that develops inside the hollow cathode acts as a source of electrons for the electron beam. Electrons emitted by the internal walls of the cathode (following bombardment by ions, fast neutrals, and photons) are accelerated through an internal voltage drop of several hundred volts. These electrons are electrostatically trapped inside the hollow cathode and lose most of their energy in exciting and ionizing collisions that sustain the internal plasma. The majority of the discharge voltage drop, however, occurs in the external cathode dark space region shown in Fig. 1(a). This external dark space presents a voltage drop of several kilovolts to the electrons which emerge from the hollow cathode plasma, thereby forming the electron beam. Hollow cathode electron guns have two modes of operation. One mode is a high impedance one in which the electron beam is produced, and the other is a low impedance mode where no electron beam is produced. Operation in the beam mode occurs over a limited range of current and pressure. ${ }^{11.12}$ When these two parameters are

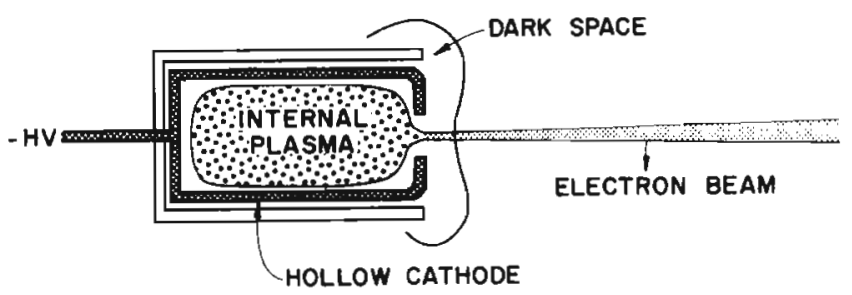

(a)

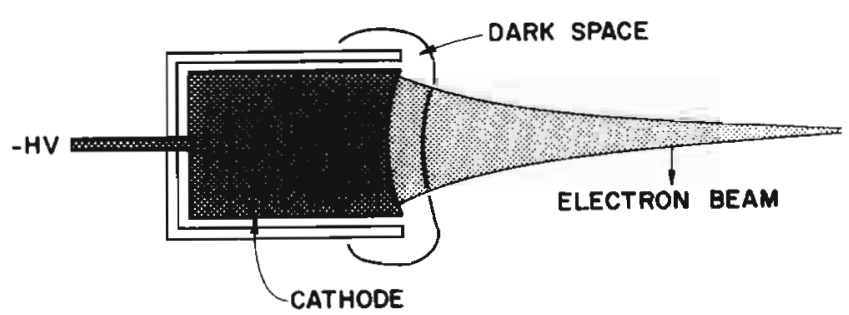

(b)

FIG. 1. Schematic repesentation of glow discharge electron guns. (a) Hollow cathode electron gun. (b) Front face secondary emission cold cathode electron gun. 
not properly chosen the extenal dark space vanishes, production of the electron beam ceases, and the discharge then operates in the low impedance mode. In this mode the cathode operates as a regular hollow cathode, ${ }^{13}$ where the voltage drop is a few hundred volts and a positive column occupies the distance between electrodes. This low impedance mode of operation prevents electron beam production. Instabilities in the discharge can switch the discharge from the electron beam mode to the low impedance mode, and this is undesirable for stable operation of the electron gun. We briefly discuss below hollow cathode electron guns operating in the $10^{-2}$ - to 1 -Torr pressure region.

The pressure $P$, at which a hollow cathode electron gun will operate in the high impedance, electron beam mode, is determined by the internal cathode diameter $D$. Consequently, the scaling gas discharge law $P D=C$ can be used to guide the design of these electron guns, ${ }^{12}$ where $C$ is a constant dependent upon both the nature of the gas and the cathode surface. Using a 4.7-mm cathode hole diameter, we were able to operate hollow cathode electron guns in the beam mode at pressures up to 1.4 Torr in helium and 0.4 Torr in argon. We obtained electron beam generation at the $1-\mathrm{kW}$ power level at beam currents up to $0.1 \mathrm{~A} .{ }^{11}$ We also obtained "sheet electron beams" $20-\mathrm{cm}$ long and several millimeters wide by operating a transverse hollow cathode electron gun. ${ }^{12}$ Beam generation efficiencies of $50 \%-70 \%$ are typical for solid wall hollow cathode guns. ${ }^{11}$ It is noteworthy that perforated wall hollow cathode guns have also been successfully operated. ${ }^{14,15}$ The cathode wall in this latter case is constructed of metallic mesh. These mesh electron guns are very simple; however, their operating efficiency is considerably lower, typically $20 \%$ to $30 \%$. We will emphasize in the remainder of this paper "front face secondary emission" electron guns. Such devices can operate at higher pressures and provide larger electron beam currents with higher operating efficiency. For a more complete discussion of hollow cathode electron guns, see Refs. 2, 11, and 12.

Figure 1(b) shows a "front face secondary emission" type of electron gun. In this case, electron emission from the cathode wall is produced following bombardment of the cathode surface both by ions and by fast neutrals created by resonant charge transfer in the cathode sheath. The secondary electrons produced at the cathode surface are accelerated along the electric field lines through the cathode dark space to form a well-collimated electron beam. This is clearly shown in Fig. 2 where the electron-beam-created plasma is visible. The cathode face was made concave to focus the electron beam electrostatically. To confine the emission to the cathode front face, all other cathode surfaces were shielded. In contrast with hollow cathode electron guns, secondary emission electron guns present only one mode of operation and, hence, represent a considerable practical advantage for stable electron beam production. Secondary emission electron guns can operate at slightly higher pressures $(0.1-3$ Torr) than the hollow cathode guns. Operation at even higher pressures is also possible, however, the electron beam becomes poorly collimated as the gas density increases.

A cathode material with a high secondary electron emission coefficient by ion bombardment $\gamma$ is required for

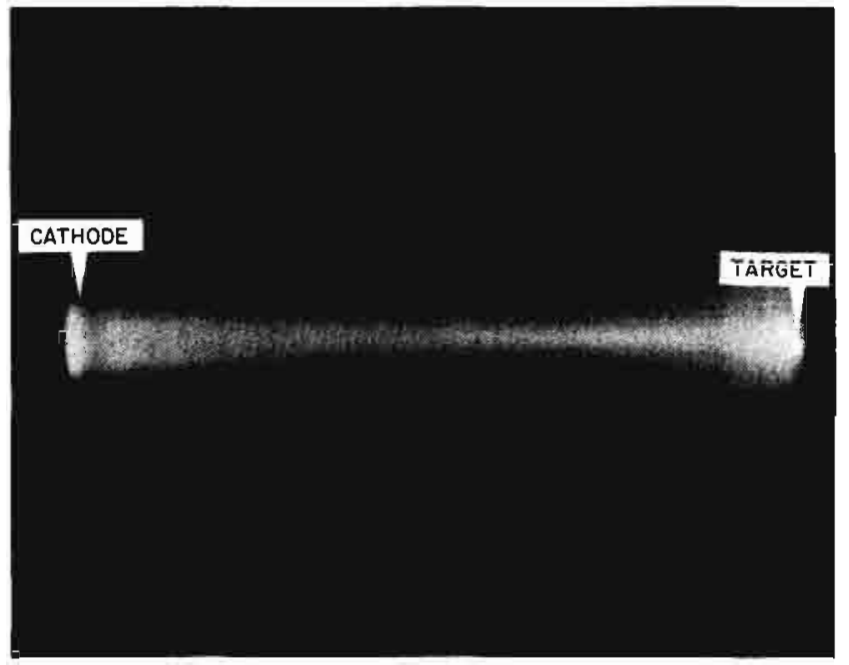

FIG. 2. Electron beam plasma formed by a front face secondary emission electron gun.

efficient electron production using cold cathodes. Cathodes with a low sputtering yield are also required for prolonged cathode lifetime. In the next section we compare the results of beam generation using various cathode materials. The best cathode materials possess both a high secondary emision coefficient and a low sputtering yield.

\section{EFFECT OF CATHODE MATERIALS ON BEAM GENERATION}

We constructed cathodes of 10 different materials. Each cathode was $3.1 \mathrm{~cm}$ in diameter with a 6-cm radius of curvature concave front face. The cathodes were surrounded by an insulating ceramic tube to confine the emission solely to the cathode front face. The distance between the cathode shield and the cathode was approximately $1 \mathrm{~mm}$.

Table I lists the cathode materials tested, the maximum electron beam discharge current obtained, and the relative sputtering erosion of that cathode material. Cathode sputtering was evaluated only qualitatively by comparing the state of the cathode surface before and after a discharge and by observing the spontaneous emission from cathode material species in the glow discharge just in front of the cathode. In the case of materials with a high sputtering yield, the characteristic spectral lies of the cathode materials are strong in the emission spectrum while low sputtering yield cathode materials had weak spectra. The first five materials listed in Table I are both good sources of secondary electrons and at the same time have a low sputtering yield. Consequently, they are judged to be good cathode materials. Wellcollimated multikilowatt dc electron beams have been obtained with all five of these cathodes. Graphite has the lowest sputtering yield but a low secondary electron emission coefficient, $\gamma$, and can be used when small $(0.1 \mathrm{~A})$ electron beam discharge currents are sufficient. The last five materials listed in Table I are considered poor glow discharge cathode materials. For example, copper beryllium has a high secondary electron emission coefficient by ion bombardment ( $\gamma=2$ for 3-keV ions), ${ }^{16}$ but unfortunately a high sputtering rate of cathode materials is observed. Thus, while it is possi- 
TABLE I. Characteristics of glow discharge electron gun cathode materials.

\begin{tabular}{|c|c|c|c|}
\hline Cathode material & Composition & $\begin{array}{c}\text { Maximum } \\
\text { current }(A) \\
(3.1-c m-d i a m \text { cathode })\end{array}$ & Sputtering \\
\hline 1. Aluminum & $\begin{array}{l}\text { coated with a } \\
\text { thin oxide layer }\end{array}$ & 1.2 & low \\
\hline 2. Magnesium & $\begin{array}{l}\text { coated with a } \\
\text { thin oxide layer }\end{array}$ & 1.2 & low \\
\hline 3. Lanthanum hexaborate & & 0.8 & acceptable \\
\hline $\begin{array}{l}\text { 4. Sintered } \\
\text { Molybdenum- } \mathrm{Al}_{2} \mathrm{O}_{3}\end{array}$ & $50-50 \%$ by weight & 1.0 & acceptable \\
\hline $\begin{array}{l}\text { 5. Sintered } \\
\text { Molybdenum-MgO }\end{array}$ & $50-50 \%$ by weight & 0.6 & acceptable \\
\hline 6. Graphite & & 0.1 & low \\
\hline 7. Copper & & 0.05 & very high \\
\hline 8. Copper-beryllium & $98-2 \%$ & 0.05 & very high \\
\hline 9. Stainless steel & & 0.05 & high \\
\hline 10. Molybdenum & & 0.05 & high \\
\hline
\end{tabular}

ble to increase the current of the glow discharge, the rapid destruction of the cathode is enhanced by sputtering. Even at small discharge currents, a green cloud is visually observed in the vicinity of the cathode. Current values below $0.05 \mathrm{~A}$ for the maximum discharge current in Table I have little significance because a well-defined electron beam is not observed. Similar behavior is observed when stainless steel and molybdenum are used as cathode materials. These materials are also poor electron emitters following ion bombardment. Again, in both cases it is possible to observe with the eye a distinctive colored emission characteristic of the sputtered cathode material.

Next, we will discuss in more detail the characteristics of electron beam production with the five cathode materials considered practical. These will be discussed in three groups: aluminum and magnesium; lanthanum hexaborate; and sintered ceramic-metal composites.

\section{A. Aluminum and magneslum cathodes with oxide coatings}

Both aluminum and magnesium have strongly adherent native oxide layers. When covered by a thin oxide layer these cathode materials are excellent emitters of secondary electrons by ion bombardment, possessing a secondary emission coefficient nearly 10 times greater than that of the pure metals. These oxide coatings are also highly resistant to sputtering. However, when operated in a pure noble gas atmosphere at high current densities $\left(100 \mathrm{~mA} / \mathrm{cm}^{2}\right)$, energetic ions and neutral atoms which impinge on the cathode surface soon sputter off the native oxide layer. When this coating is removed, the secondary electron emissivity of the cathode drops nearly an order of magnitude and the material of the cathode itself starts to rapidly sputter into the discharge. This transition can be seen by the eye as a change of color in the light emitted from the discharge region close to the cathode. It is possible, however, to maintain a stable oxide layer by adding a few millitorr of $\mathrm{O}_{2}$ into the discharge. In this way, the cathode oxide layer is continuously restored via plasma-induced oxidation and we observed no change in the emission characteristics after $10 \mathrm{~h}$ of operation at high $(100$ $\mathrm{mA} / \mathrm{cm}^{2}$ ) current densities. The $I-V$ characteristics of the electron beam glow discharge with an aluminum cathode 3.1 $\mathrm{cm}$ in diameter covered by a thin $\mathrm{Al}_{2} \mathrm{O}_{3}$ film are shown in Fig. 3(a) with He pressure as a parameter. This figure shows generation of electron beam discharge currents over $1 \mathrm{~A}$ (cathode current density $>0.15 \mathrm{~A} / \mathrm{cm}^{2}$ ) and that discharge powers up to $5 \mathrm{~kW}$ have been obtained. This figure also shows that the impedance of the electron beam glow discharge is significantly reduced when an axial magnetic field $(1-4 \mathrm{kG})$ is applied in the electron beam drift region. The magnetic field increases the plasma density, and subsequently, the ion flux to the cathode, thereby enhancing secondary electron emission from the cathode and lowering the discharge impedance.

We performed calorimetric measurements to determine the efficiency at which the electron beam is generated. A copper calorimeter was situated $13 \mathrm{~cm}$ from the cathode emitting surface. The calorimeter was supported only by a thin wall stainless-steel tube of poor heat conductance to ensure good thermal insulation. The temperature of the calorimeter was continuously measured with a thermocouple and its variation with time plotted with an $\mathrm{x}$-t chart recorder. The discharge current $I$ and voltage $V$ of the glow discharge were also monitored and recorded. The efficiency $E_{F}$, with which beam electrons are generated by the electron gun was then calculated as

$$
E_{F}=\frac{\frac{d T}{d t} M \dot{C}(T)}{I V},
$$

where $M$ is the mass of the calorimeter and $C(T)$ is the specific heat of copper. The results of these measurements for an electron gun with an aluminum cathode in a $\mathrm{He}$ ambient (with $20 \mathrm{mTorr}$ of $\mathrm{O}_{2}$ ) are shown in Fig. 3(b). The electron 

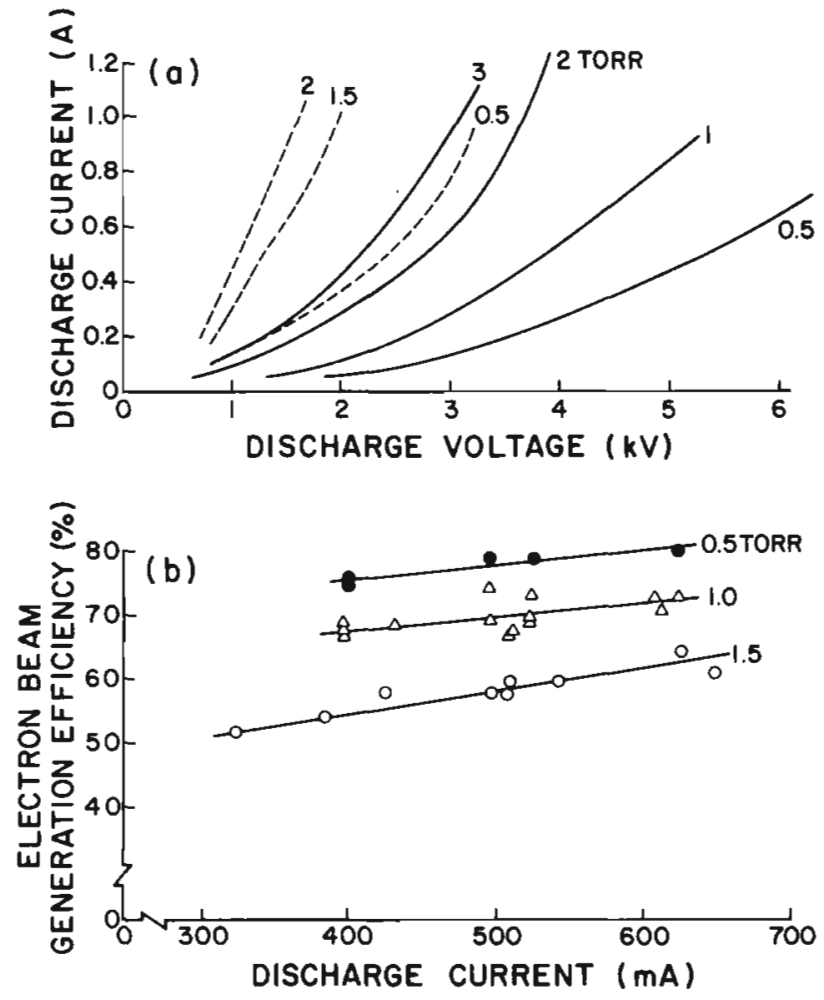

FIG. 3. (a) $V$-I characteristics of the aluminum cathode electron-beam discharge in helium with $20 \mathrm{~m}$ Torr of oxygen added to the discharge chamber. Solid line: without magnetic field. Dashed line: operating the electron gun $13 \mathrm{~cm}$ from a solenoid producing a magnetic field of $3.2 \mathrm{kG}$. Fringing field at the cathode front face $40 \mathrm{G}$. (b) Electron-beam generation efficiency as a function of discharge current for an aluminum cathode. The He pressure in Torr is shown. $20 \mathrm{~m}$ Torr of oxygen was also added to the discharge chamber.

beam generation efficiency is observed to increase as the total pressure decreases and as the cathode current increases. This is attributed to the increase of the secondary emission coefficient as a function of the energy of the impinging ions. ${ }^{17}$ The energy of these ions and associated fast neutrals, created by charge transfer, increases with the discharge voltage. ${ }^{18} \mathrm{~A}$ maximum electron beam generation efficiency of $80 \%$ was measured at 0.5 Torr of helium and a beam current of $0.65 \mathrm{~A}$.

Magnesium covered with a thin oxide layer is also an excellent emitter of secondary electrons following ion bombardment. As in the case of aluminum, the oxide has a low sputtering yield. Again, if the cathode is to be continuously operated in pure noble gas environments at a high current density $\left(0.1 \mathrm{~A} / \mathrm{cm}^{2}\right)$, then a few millitorr of $\mathrm{O}_{2}$ is needed to compensate for erosion of the cathode oxide layer. We discovered that electron guns with magnesium cathodes create glow discharges with lower impedance than the ones obtained with aluminum cathodes of the same geometry. We have obtained electron beam discharge currents of $1.2 \mathrm{~A}$ at an energy of $1.5 \mathrm{keV}$ by operating a $\mathrm{Mg}$ electron gun with a $3.1-\mathrm{cm}$-diam cathode in 1 Torr of helium with $10 \mathrm{mT}$ Torr of oxygen.

We have previously measured the energy spectrum of the transmitted electron beam, created by a magnesium cathode coated with a thin oxide layer, using an electrostatic energy analyzer. ${ }^{19}$ Electron beam energy distributions were measured at pressures between 0.15 and 0.8 Torr, currents between 60 and $700 \mathrm{~mA}$, and discharge voltages between 1 and $2.5 \mathrm{kV}$. The glow-discharge-generated electron beams have an energy width at half-maximum of $100-300 \mathrm{eV} .^{19}$ The energy width was observed to decrease for all pressures as the current was incremented. Also, at certain pressurecurrent conditions the electron beam energy profile was observed to degrade abruptly into a broad distribution. This change was coincident with the sudden appearance of a plasma region with a very intense luminosity and with the emission of intense microwave radiation. This phenomena was attributed to the generation of plasma oscillations driven by the electron beam and is treated in more detail elsewhere. ${ }^{19}$

\section{B. Lathanum hexaborate}

$\mathrm{LaB}_{6}$ has been used in the past as a thermionic emitter. ${ }^{20} \mathrm{We}$ have used $\mathrm{LaB}_{6}$ as a cold cathode in glow discharge electron guns. We observed that after exposure to the ambient atmosphere lathanum hexaborate is a good electron emitter by ion bombardment alone. However, after operation in a pure noble gas atmophere, an increasing voltage was needed to maintain a constant current. When a small amount of $\mathrm{O}_{2}$ (20 mTorr) was introduced into the discharge the cathode rapidly recovered its electron emission. A thin oxide coating is, as in the case of $\mathrm{Al}$ and $\mathrm{Mg}$ cathodes previously discussed, apparently of fundamental importance in providing a high secondary electron emission coefficient, $\gamma$. The $I$ - $V$ characteristics of a 3.1-cm-diam $\mathrm{LaB}_{6}$ cathode operating in a helium atmosphere with $20 \mathrm{mTorr}$ of $\mathrm{O}_{2}$ are shown in Fig. 4(a). Well-collimated electron beam glow discharges with discharge currents up to $0.8 \mathrm{~A}$ have been obtained. $\mathrm{Ca}$ lorimetric measurements of the electron beam production efficiency are shown in Fig. 4(b). They indicate that electron beam generation efficiencies up to $70 \%$ are obtainable with $\mathrm{LaB}_{6}$ cathodes in a helium atmosphere with a 20-mTorr partial pressure of oxygen.

\section{SIntered ceramic-metal cathodes}

The need for $\mathrm{O}_{2}$ in the plasma to achieve prolonged operation of $\mathrm{Al}, \mathrm{Mg}$, and $\mathrm{LaB}_{6}$ cathodes can be undesirable in some applications. For example, if the electron guns are to be used for laser excitation, the presence of oxygen in the laser active medium can in some cases interfere with the laser excitation mechanisms. We have therefore developed cathode materials which can operate in a pure noble gas atmosphere without the need of a partial pressure of oxygen.

The materials are obtained by hot press sinterization of molybdenum and aluminum oxide or molybdenum and magnesium oxide particles $10 \mu \mathrm{m}$ in diameter. This ceramicmetal composite has unique cathode properties. The oxide particles have a high secondary electron emission coefficient while the molybdenum particles make the material a good conductor of electricity enabling dc operation of the electron beam. We experimented with several different ratios by weight of Mo to oxide particles to find the optimum proportions for beam generation. We found that in the case of Mo$\mathrm{MgO}$, equal portions by weight worked well. This is equiva- 

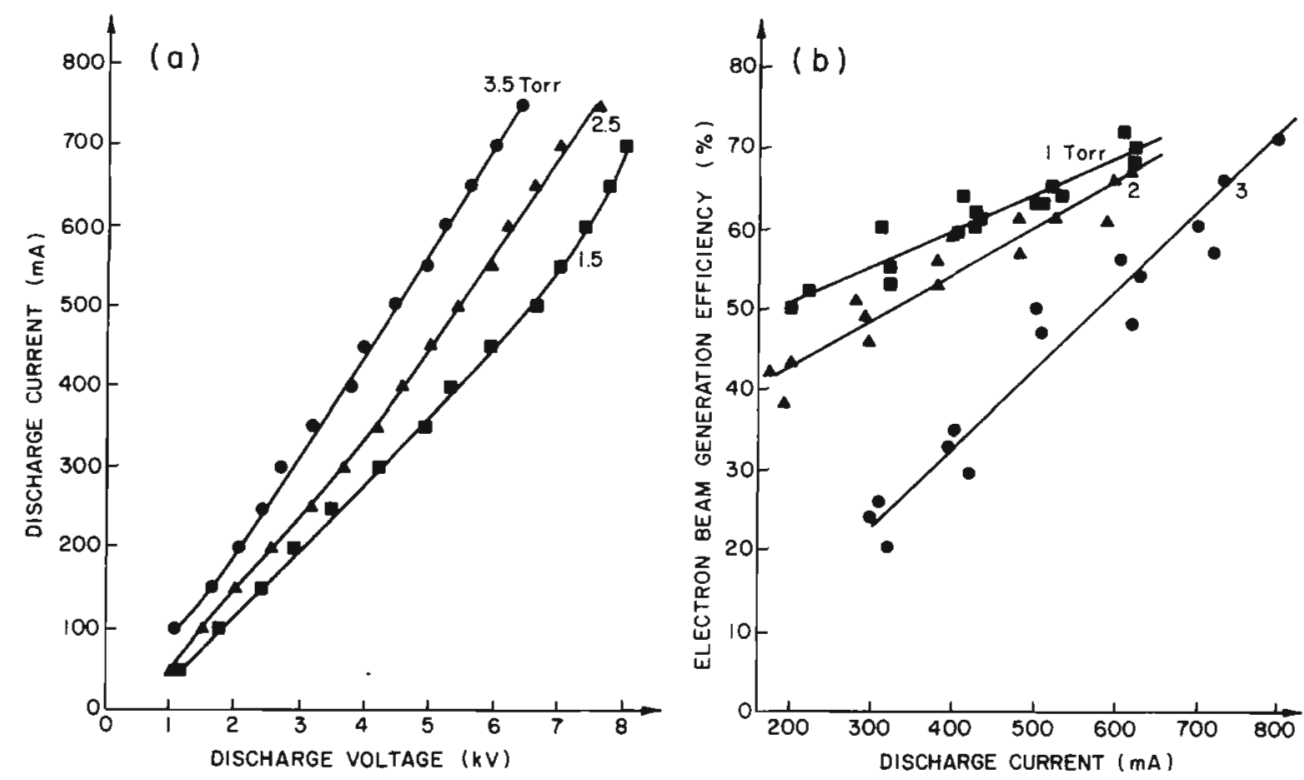

FIG. 4. (a) $V \cdot I$ characteristics of the helium glow discharge obtained using a $3.1-\mathrm{cm}$-diam, 6-cm-radius-of-curvature lanthanum hexaborate cathode. $20 \mathrm{mT}$ Trr of oxygen was added to the discharge chamber. (b) Electron-beam generation efficiency as a function of discharge current for the lanthanum hexaborate electron gun. The He pressure is in Torr. $20 \mathrm{mTorr}$ of oxygen was added to the discharge. lent to approximately $74 \% \mathrm{MgO}$ and $26 \%$ Mo by volume. Consequently, the ions bombarding the cathode surface mostly impinge on the oxide particles, allowing for efficienct electron beam production. Increasing the amount of $\mathrm{MgO}$ results in an undesirable decrease of the electrical conductivity of the cathode preventing dc operation. In the $\mathrm{Mo}-\mathrm{Al}_{2} \mathrm{O}_{3}$ sintered mixtures, equal portions by weight of $10-\mu \mathrm{m}$-diam particles give good results as cathode material. Figures 5(a) and $5(\mathrm{~b})$ show the $V-I$ characteristics and electron beam production efficiency of a glow discharge using a 3.1-cm-diam Mo-MgO cathode operating in helium. These figures show that electron beam discharge powers of $3 \mathrm{~kW}$ and discharge currents up to $0.6 \mathrm{~A}$ have been obtained with these electron guns at efficiencies up to $75 \%$. Figure 6(a) shows the $V-I$ characteristics of a discharge using $\mathrm{Mo}-\mathrm{Al}_{2} \mathrm{O}_{3}$ cathode, also $3.1 \mathrm{~cm}$ in diameter. In this case the maximum discharge current obtained was $1 \mathrm{~A}$. The electron beam generation efficiencies as a function of current with helium pressure as parameter are shown in Fig. 6(b). Beam generation efficiencies up to $75 \%$ were demonstrated.

In summary, both sintered ceramic-metal mixtures constitute good cathode materials, producing multikilowatt elecron beams in a pure helium atmosphere at efficiencies up to $75 \%$. The $\mathrm{MgO}-\mathrm{Mo}$ cathode fractured after a 0.6-A discharge, probably due to a poor thermal shock resistance.
This prohibited tests at higher currents and explains why the maximum current obtained with the $\mathrm{MgO}-\mathrm{Mo}$ cathode was smaller than with the $\mathrm{Al}_{2} \mathrm{O}_{3}-\mathrm{Mo}$ cathode.

\section{GLOW DISCHARGE ELECTRON GUN GEOMETRIES}

Electron beams of tailored geometries can be realized with front face secondary emission glow discharge electron guns. The geometry of the cathode face largely determines the shape of the resulting electron beam. However, as discussed previously, the cathode material needs to have a high secondary electron emission coefficient by ion bombardment for efficient electron beam generation and a low sputtering yield for prolonged lifetime. If a multikilowatt dc electron beam is desired on a continuous basis, the cathode must be water cooled. Usually we make the water-cooled body of the cathode out of copper, and press fit the selected cathode material into this cooled section. This two-piece construction allows for efficient cooling of the porous cathodes made of sintered materials. The entire cathode is completely surrounded by an insulating shield that confines the secondary emission to the unshielded cathode surface. The distance between the insulating shield and the cathode is approximately $1 \mathrm{~mm}$ and is always less than an electron collision mean free path. A grounded metallic shield has also been used.
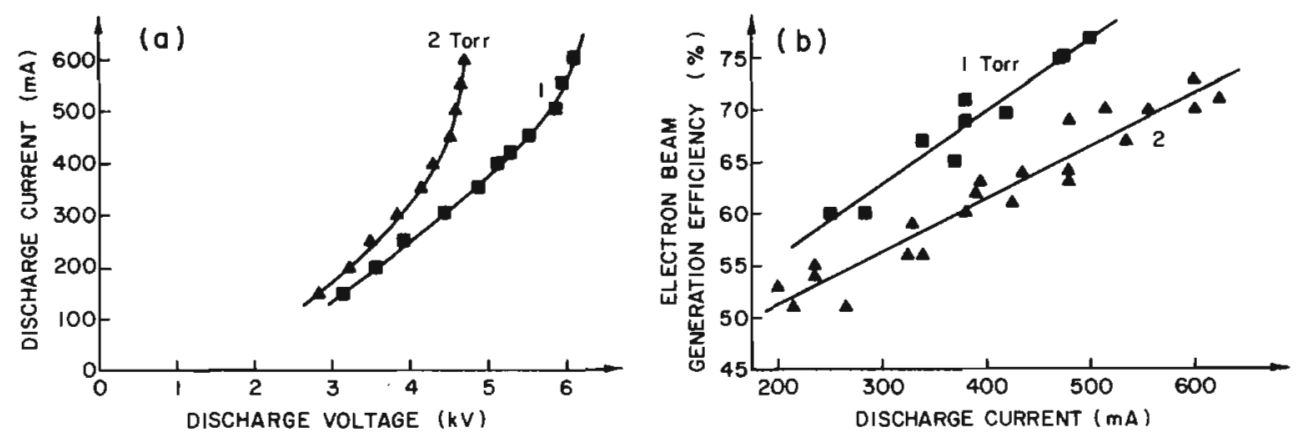

FIG. 5. (a) $V-I$ characteristics of the helium glow discharge obtained using a sintered $\mathrm{MgO}$ ( $50 \%$ by weight $-\mathrm{Mo}$ concave cathode $3.1 \mathrm{~cm}$ in diameter and with a $6-\mathrm{cm}$ radius of curvature. (b) Electron beam generation efficiency as a function of discharge current for the sintered MgO-Mo electron gun. 


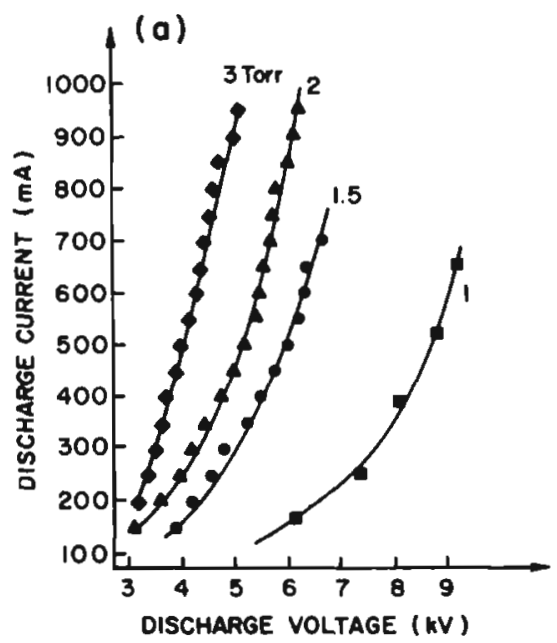

The primary application of glow discharge electron guns in our work has been in the excitation of cw ion lasers. Figure 7 shows the structure of an electron gun developed for this purpose. The electron gun geometry (doughnut-like) provides a clear $0.5-\mathrm{cm}$-diam optical path throughout the axis. This permits one to easily match the electron-beamcreated plasma volume with the volume of an optical resonator. To confine the emission to the cathode front face only, the rest of the cathode walls are shielded. Specifically, a ceramic tube $\left(99.8 \% \mathrm{Al}_{2} \mathrm{O}_{3}\right)$ covers the external cathode walls and a quartz tube shields the inner cathode walls. The cathode was made of aluminum $3.1 \mathrm{~cm}$ in diameter and was operated in a helium atmosphere which contained approximately $20 \mathrm{mTorr}$ of $\mathrm{O}_{2}$. The rest of the cathode was made of copper and was water cooled for adequate heat dissipation at multikilowatt dc operating conditions. The cathode front face was made concave to focus the electron beam as shown in Fig. 1(b). We have used both 6 and $9 \mathrm{~cm}$ as a radius of curvature. Similar electron guns with cathodes made of sintered metalceramic materials described in Sec. III were also successfully used to excite cw ion lasers. The position of the anode is not important so we usually use the stainless-steel vacuum chamber in which the electron gun operates as the anode. The use of this electron gun design in exciting $\mathrm{cw}$ lasers is discussed further in Sec. $V$ of this paper.

Figure 8 shows a broad area $(7.5 \mathrm{~cm}$ in diameter) electron gun constructed for the purpose of electron beam annealing of ion-implanted silicon wafers. The cathode was made of a sintered Mo-MgO mixture of equal portions by weight. The cathode was supported by an aluminum piece which was not water cooled in this case as only short electron

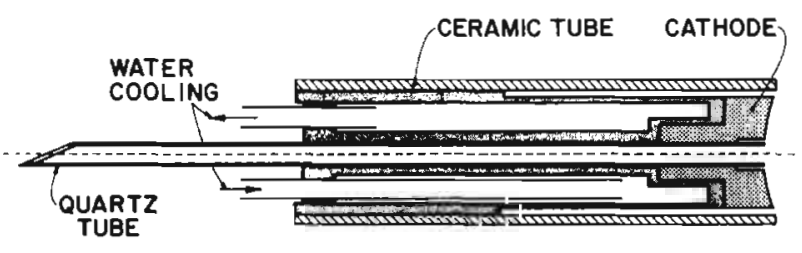

FIG. 7. Structure of the glow discharge electron gun for longitudinal laser excitation. beam operating times $(60 \mathrm{sec})$ were required for this application. The broad area cathode was surrounded by a quartz shield which confined the emission to the front face. Discharge currents up to $700 \mathrm{~mA}$ and discharge powers of $3 \mathrm{~kW}$ $\left(70 \mathrm{~W} / \mathrm{cm}^{2}\right)$ were easily obtained. The $I-V$ characteristics of this electron gun operating in helium are shown in Ref. 10.

Figure 9 shows the structure of an electron gun designed to produce a line source $5-\mathrm{cm}$ long and approximately $2-\mathrm{mm}$ wide at the focal plane. This electron gun has been used for both annealing silicon wafers as well as recrystallizing polysilicon films. The geometry of this electron gun is similar to the transverse hollow cathode electron gun for plasma excitation described in Ref. 12; the main difference being that the cathode shown in Fig. 9 is slotless. Notice that the operation of this electron gun is similar to the electron guns previously described, except for the geometry, and consequently does not need further discussion.

\section{APPLICATIONS OF GLOW DISCHARGE ELECTRON GUNS}

\section{A. Excitation of $\mathbf{c w}$ ion lasers}

We have used the electron guns described in Sec. II and IV to excite helium-metal-vapor gas mixtures and obtain $\mathrm{cw}$

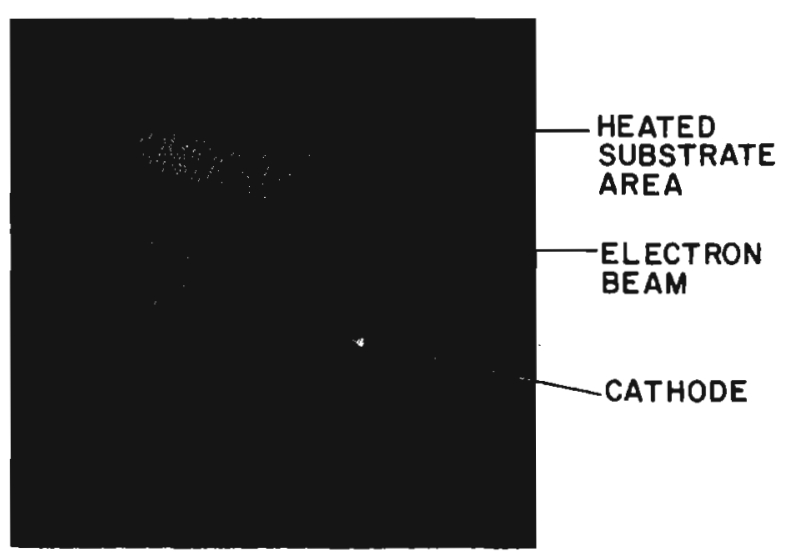

FIG. 8. Experimental setup used to anneal $n$-type silicon wafers implanted with $30-\mathrm{keV}$ boron ions to a total dose of $5 \times 10^{15}$ ions $/ \mathrm{cm}^{2}$. 


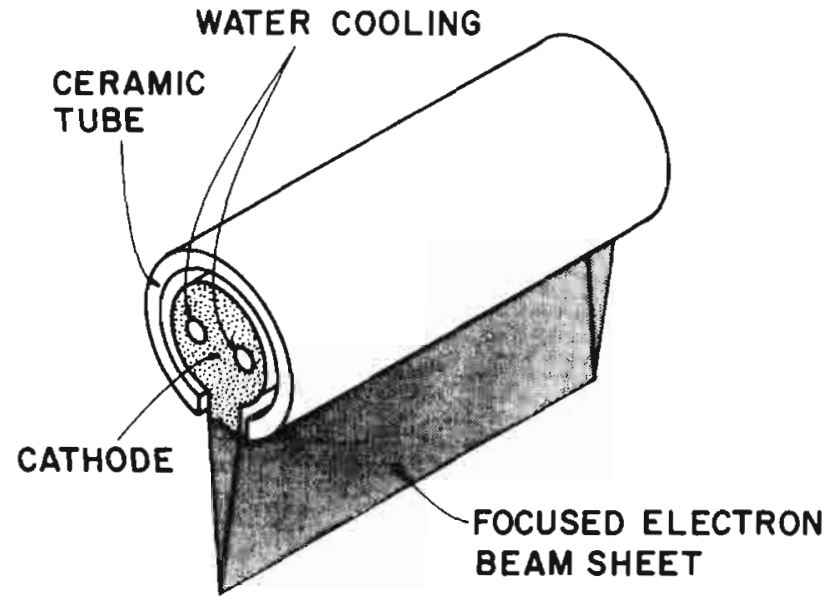

Fig. 9. Structure of an electron gun designed to produce an electron sheath 5-cm long and approximately $2-\mathrm{mm}$ wide at the focal plane. This sheath geometry is used for annealing silicon wafers and recrystallizing polysilicon wafers.

laser action in seven different singly ionized metallic species. $^{4-8}$ We successfully used both, oxide-coated aluminum cathodes ${ }^{21}$ and sintered metal-ceramic cathodes. In the first case we introduced 10-20 mTorr of oxygen into the gas mixture, to allow stable electron emission over prolonged periods of time. In all seven laser media, the presence of the oxygen impurity did not affect the laser output power in a measurable way. The axial path of the electron guns allows for an easy overlap of the electron-beam-created plasma with the volume of the optical resonator as show in Fig. 10. The excitation scheme shown in this figure uses two electron guns that produce two counter propagating electron beams. The electron beams are kept collimated along the 1-m-long plasma tube by use of an axial magnetic field of $1-4 \mathrm{kG}$. Using this electron beam excitation scheme we have obtained $\mathrm{cw}$ laser radiation on more than 40 ion transitions. ${ }^{22}$ A cw laser power output of $1.2 \mathrm{~W}$, for example, was obtained on the 4911.6 and $4924.0-\AA$ transitions of $\mathrm{Zn}$ II. This repesents an order of magnitude increase in the laser output power and efficiency previously obtained for these metal vapor transitions using hollow cathode discharges. ${ }^{23}$

In summary, electron beam pumping is a new way to excite ion lasers that has the potential of increasing both the operating efficiency of these devices as well as the output power. ${ }^{23}$

\section{B. Large area glow discharge electron beam annealing of lon-Implantation damage}

We have thermally annealed ion-implant damage in silicon wafers using a broad area $(7.5 \mathrm{~cm}$ in diameter) glow discharge electron gun. This allowed for irradiation of an entire 3-in. $(7.5-\mathrm{cm})$ wafer without beam or wafer scanning as did previous investigators. ${ }^{24}$ An electron beam power of up to $3 \mathrm{~kW}$ at a current of $0.7 \mathrm{~A}$ was created using a magnesium oxide-molybdenum cathode. The electron beam was produced in helium at a pressure between 0.1 and 2 Torr. The experimental setup shown in Fig. 8 was used to anneal $n$ type silicon wafers implanted with $30-\mathrm{keV}$ boron ions to a total dose of $5 \times 10^{15}$ ions $/ \mathrm{cm}^{2}$. Samples were isochronally annealed for $15 \mathrm{sec}$ at different electron beam power densities and the change in sheet resistivity was measured. The reduction of sheet resistivity exhibited a threshold of $160 \mathrm{~J} /$ $\mathrm{cm}^{2}$ and reached $10 \%$ of the initial value at a total energy of $725 \mathrm{~J} / \mathrm{cm}^{2}$. Annealing of doped polysilicon and silicide films was also achieved.

In summary, broad area glow discharge electron guns provide enough power density to allow processing of large area wafers in a few seconds without requiring focusing and/ or scanning of the electron beam.

\section{Electron-beam-assisted chemical vapor deposition}

We have used glow discharge electron beams to deposit $\mathrm{SiO}_{2}$ and $\mathrm{Si}_{3} \mathrm{~N}_{4}$ films on silicon wafers at low substrate temperatures $\left(200^{\circ}\right.$ to $\left.400^{\circ} \mathrm{C}\right)$. The need for low temperautre semiconductor processing becomes increasingly important as semiconductor device structures move to submicron dimensions. Low temperature processes reduce dopant redistribution, wafer warpage, and crystalline defect generation each of which are induced by high temperature processing. We used electron beam dissociation of the reactants as a new CVD technique compared to conventional rf plasma assisted CVD. In contrast with radio frequency CVD, where the reaction volume fills almost all of the chamber, in the electron beam scheme the reaction is confined to the volume determined by the electron-beam-created plasma. In this way, the amount of reactants lost to the walls is largely reduced as is the undesired sputtering from chamber walls. We used both aluminum and sintered cathodes to produce rectangular electron beam sheets $(2 \times 30 \mathrm{~mm})$ located parallel to the wafer surface. The beam electrons collide with the reactant gas molecules dissociating and creating free radial species that include excited atoms and molecules, as well as positive and negative ions. These species diffuse across a boundary layer to the heated substrate. Nucleation and film growth occurs at absorption sites leading to the formation of islands. The process continues with coalescence of these islands to form a continuous film. The experimental setup we used to obtain electron beam induced CVD of $\mathrm{SiO}_{2}$ and $\mathrm{Si}_{3} \mathrm{~N}_{4}$ is shown in Fig. 11. We expect the electron beam CVD technique to be

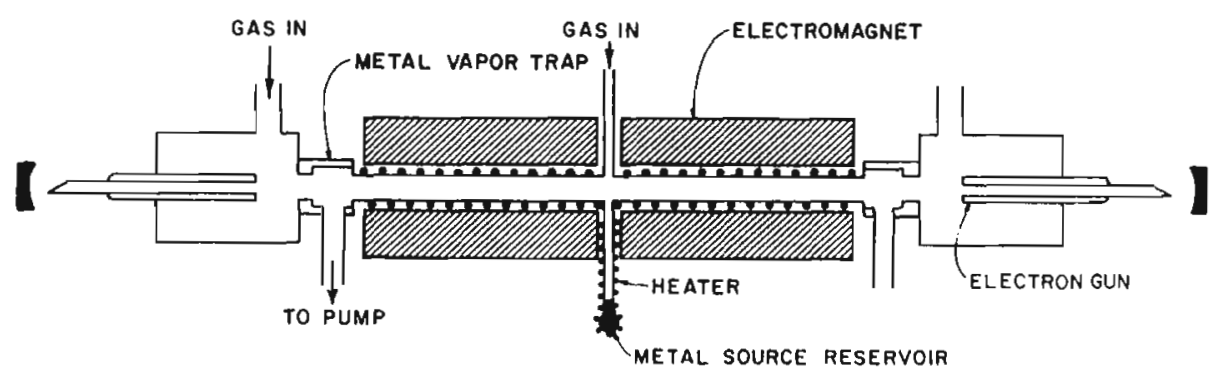

FIG. 10. Setup used for electron beam pumping of $\mathrm{cw}$ ion lasers utilizing two electron guns that produce two counter propagating electron beams. Electromagnet keeps the two beams well collimated. 


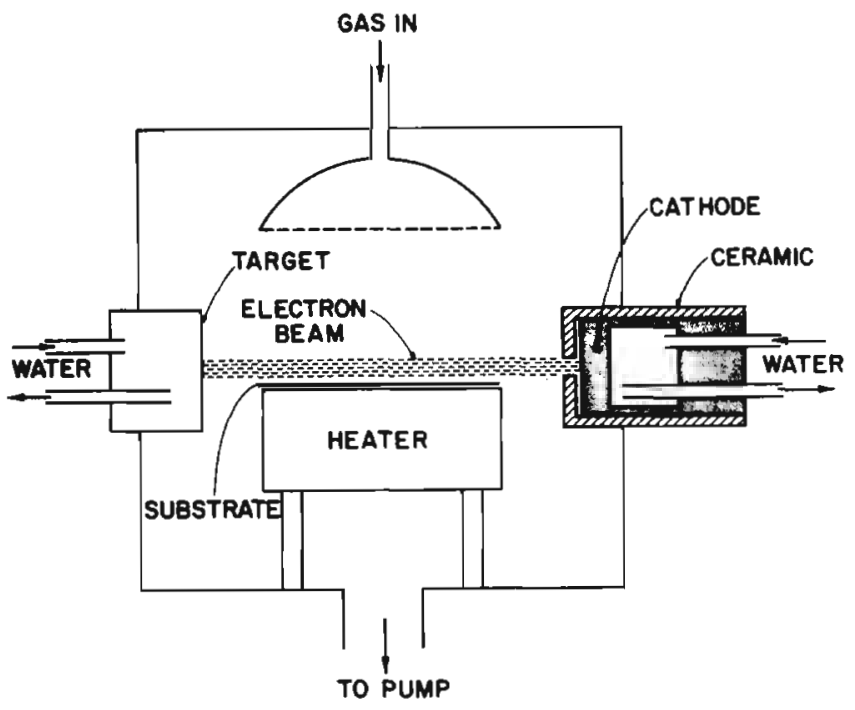

FIG. 11. Experimental setup for electron beam $\mathrm{CVD}$ of $\mathrm{SiO}_{2}$ and $\mathrm{Si}_{3} \mathrm{~N}_{4}$. The wafer is located on the substrate heater.

useful as a means to deposit a large variety of insulating, metallic, as well as semiconducting, films over large areas.

\section{Other suggested applications of glow-dlscharge- created electron beams}

Glow discharge electron guns can find other applications in experimental situations in which an electron beam is needed at pressures between $10^{-2}$ and 3 Torr; since, they can operate at these pressures without differential pumping. Glow discharge electron beams of $1 \mathrm{keV}$, for example, can be used to simulate heavier particles which ionize and excite the laser medium as in the case of a nuclear-pumped laser plasma. ${ }^{25}$ Another application is the generation of $\mathrm{x}$ rays for preionizing gas laser discharges or for $\mathrm{x}$-ray photolithography. Glow discharge electron guns could also be used as the ionization source in broad area ion sources. Unique advantages would be both the broad area of the source as well as the abundance of multiple ionized species. Finally, electron-beam-assisted unidirectional etching of microelectronic thin films and substrates is possible using the electron beam to enhance surface etching rates without the surface texturing or crystal damage that ion beams cause.

\section{SUMMARY}

Ten different electron gun cathode materials have been compared for the production of glow discharge electron beams in helium at pressures between 0.1 and 3 Torr. Aluminum and magnesium, when covered by a thin oxide layer can produce electron beams with discharge currents up to $1.2 \mathrm{~A}$ at measured beam generation efficiencies of up to $80 \%$. However, a small amount of oxygen ( 5 to $20 \mathrm{mTorr}$ ) must be present in the discharge to allow for the regrowth and maintenance of the oxide layer which is continually sputtered away by the bombardment of the cathode surface by ions and fast neutrals. A similar need for an oxide layer was observed for $\mathrm{LaB}_{6}$ cathodes. The use of sintered refractory metal-ceramic cathode materials such as $\mathrm{Mo}-\mathrm{Al}_{2} \mathrm{O}_{3}$ allowed us to produce multikilowatt electron beams at an efficiency of up to $75 \%$ in a pure noble gas atmosphere without the need for a partial pressure of oxygen. Glow discharge electron guns have been successfully used in the excitation of $\mathrm{cw}$ ion lasers, chemical vapor deposition of thin microelectronic films, and for the rapid thermal annealing of ion-implanted damage in silicon wafers. Other applications are suggested.

\section{ACKNOWLEDGMENTS}

The authors wish to thank the experimental assistance of Zeng-qi Yu (Fudan University), Lisa Happel, Jim McGinn, Allan Brown, Angus McCamant, Cameron Moore, and Lance Thompson. We also thank Don Jennings of NBS-Boulder for the loan of a power supply and Dr. W. K. Schuebel for helpful technical discussions. This work was supported by the National Science Foundation and AFOSR.

${ }^{1}$ R. A. Dugdale, J. Mater. Sci. 10, 896 (1975).

${ }^{2}$ K. L. Boring and L. A. Stauffer, Proc. Nat. Electron. Conf. 19, 535 (1963).

${ }^{3}$ R. E. Hurley and J. H. Holliday, Vacuum 28, 453 (1978).

${ }^{4}$ J. J. Rocca, J. D. Meyer, and G. J. Collins, Appl. Phys. Lett. 40, 300 (1982).

JJ. D. Meyer, J. J. Rocca, Z. Yu, and G. J. Collins, IEEE J. Quantum Electron. QE-18, $326(1982)$.

${ }^{6}$ J. J. Rocca, J. D. Meyer, and G. J. Collins, Phys. Lett. A 90, 358 (1982).

${ }^{7}$ J. J. Rocca, J. D. Meyer, and G. J. Collins, Opt. Commun. 42, 125 (1982)

${ }^{B}$ J. J. Rocca, J. D. Meyer, and G. J. Collins, IEEE J. Quantum Electron. QE-18, 1052 (1982).

${ }^{9}$ L. Thompson, J. J. Rocca, K. Emery, P. Boyer, and G. Collins, Appl. Phys. Lett. 43, 777 (1983).

${ }^{10}$ C. A. Moore, J. J. Rocca, T. Johnson, G. J. Collins, and P. E. Russell, Appl. Phys Lett. 43, 290 (1983).

''J. J. Rocca, J. D. Meyer, and G. J. Collins, Phys. Lett. A 87, 237 (1982).

${ }^{12}$ Z. Yu, J. J. Rocca, J. D.Meyer, and G. J. Collins, J. Appl. Phys. 53, 4704 (1982).

${ }^{13} \mathrm{C}$. W. Willet, Introduction to Gas Lasers: Population Inversion Mechamisms (Pergamon, Oxford, 1974).

${ }^{14}$ H. L. Van Passen, E. C. Muly, and R. J. Allen, Proc. Nat. Electron. Conf. 18, 597 (1962).

${ }^{15} \mathrm{G}$. S. Ward, Vacuum 18, 507 (1968).

${ }^{16}$ M. J. Higatsberger, H. L. Demorest, and A. O. Nier, J. Appl. Phys. 25, 883 (1954).

${ }^{17} \mathrm{G}$. Carter and J. S. Colligon, Ion Bombardment of Solids (Elsevier, New York, 1968).

${ }^{18}$ W. Davis and T. A. Vanderslice, Phys. Rev. 131219 (1963).

${ }^{19}$ Z. Yu, J. J. Rocca, and G. J. Collins, J. Appl. Phys. 54, 131 (1983).

${ }^{20}$ A. N. Broers, J. Appl. Phys. 38, 1991 (1967).

${ }^{21}$ J. J. Rocca, J. D. Meyer, Z. Yu, M. Farrell, and G. J. Collins, Appl. Phys. Lett. 41, 811 (1982).

${ }^{22}$ J. J. Rocca, J. D. Meyer, Z. Yu, and G. J. Collins, Appl. Phys. B 28, 239 (1981).

${ }^{23}$ J. J. Rocca, J. D. Meyer, and G. J. Collins, Appl. Phys. Lett. 43, 37 (1983).

${ }^{24}$ N. J. Ianno, J. T. Verdeyen, S. S. Chan, and B. S. Streetman, Appl. Phys. Lett. 39, 622 (1981).

${ }^{25}$ A. M. Pointu, Laboratoire de Physique des Gas et Plasmas, Universite de Paris-Sud (private communication). 